Rodrigues: None declared, Helena Canhão: None declared, Nélia Gouveia: None declared, Mónica Eusébio: None declared, Sofia Ramiro Grant/research support from: MSD, Consultant for: AbbVie, Lilly, MSD, Novartis, Pfizer, Sanofi, Speakers bureau: AbbVie, Lilly, MSD, Novartis, Pfizer, Sanofi, Jaime Branco: None declared DOI: 10.1136/annrheumdis-2019-eular.6400

\section{THU0465 PHARMACOKINETICS AND TOXICOKINETICS STUDIES OF A SUSTAINED RELEASE LIPOSOMAL FORMULATION OF DEXAMETHASONE SODIUM PHOSPHATE (TLC599) FOLLOWING INTRA-ARTICULAR INJECTION IN DOGS}

Tzung-Ju Wu, Wan-Ni Yu, Ming-Ju Wu, Po-Chun Chang, Sheue-Fang Shih. Taiwan Liposome Company, Taipei, Taiwan, Republic of China

Background: Osteoarthritis $(\mathrm{OA})$ is a degenerative joint disorder with limited long-lasting treatment options. Various steroid formulations on the market are effective but required frequent intra-articular (IA) injections due to short-term symptomatic relief. IA steroids have been shown to increase cartilage loss in knee and the rapid absorption into systemic circulation could cause adverse side effects, limiting their effectiveness [1]. To circumvent these issues, TLC599, a novel sustained-release liposome formulation of dexamethasone sodium phosphate (DSP) was developed to provide a sustained $O A$ pain management over an extended period with reduced side effects and toxicity. TLC599 resulted in sustained presence in the synovial fluid without significant local and systemic side effects from $O A$ treatments following IA injection.

Objectives: To evaluate pharmacokinetics (PK) and toxicokinetics (TK) of TLC599 following IA injection in dogs.

Methods: In two studies, the dexamethasone phosphate (DP) and dexamethasone (DEX) concentration was quantified and the PK/TK profile of TLC599 was evaluated in dogs following IA injection. DSP is the sodium salt form of DP and DEX is the active form of DSP. Study\#8351851: TLC599 was administered as a single- or multiple-dose injection (once

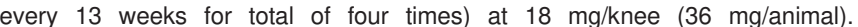
Synovial fluid was collected at 2.5, 48, 96, 168 and 360 hours post-dose from 4 animals/time point, and plasma was collected at $0.25,0.75,1.25$, 2, 4, 6, 24, 48, 96 and 168 hours post-dose from 8 animals/time point. Study\#8388198: TLC599 was administered as a single-dose injection at $18 \mathrm{mg} / \mathrm{knee}$. The synovial fluid was collected at 15, 30, 45, 90, and 120 days post-dose from 4 animals/time point.

Results: Study\#8351851: Following a single-dose IA injection of TLC599, DP concentration declined gradually after $2.5 \mathrm{hr}$ but remained detectable through $360 \mathrm{hr}$, demonstrating the prolonged local exposure in the joint (Figure 1). The PK parameters of DP and DEX in dog plasma were assessed in the multiple-dose group. The mean $C_{\max }$ and $A \cup C_{0-t}$ values of DP and DEX were comparable between the first dose (Day 1) and the fourth dose (Day 274) (Table 1), indicating there was no accumulation of systemic exposure of DP and DEX following four repeated IA injections of TLC599. By evaluating the effect on cartilage, it was also shown that the local safety profiles were similar between multiple-dose and single-dose TLC599 injections.

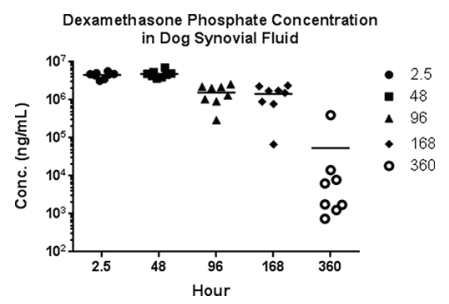

Abstract THU465 - Figure 1. Mean Concentration of DP in Dog Synovial Fluid.

Abstract THU465 - Table 1. Summary of Mean $\mathrm{C}_{\max }$ and $\mathrm{AUC}_{0-\mathrm{t}}$ of DP and DEX in Dog Plasma.

\begin{tabular}{|c|c|c|c|c|}
\hline Analyte & Dose \# & $\begin{array}{l}\text { Dose Level } \\
\text { (mg/animal) }\end{array}$ & $\begin{array}{c}\mathrm{C}_{\max } \\
(\mathrm{ng} g \mathrm{~mL})\end{array}$ & $\begin{array}{c}\begin{array}{c}\mathrm{AUC} \mathrm{C}_{0.1} \\
\text { hour }{ }^{2} \mathrm{ng}(\mathrm{mL})\end{array} \\
\end{array}$ \\
\hline \multirow{2}{*}{ Dexamethasone Phosphate } & $\begin{array}{l}\text { First Dose } \\
\text { (Day 1) }\end{array}$ & 36 & 450 & 419 \\
\hline & $\begin{array}{c}\text { Fourth Dose } \\
\text { (Day 274) }\end{array}$ & 36 & 522 & 505 \\
\hline \multirow{2}{*}{ Dexamethasone } & $\begin{array}{l}\text { First Dose } \\
\text { (Day 1) }\end{array}$ & 36 & 498 & 6385 \\
\hline & $\begin{array}{l}\text { Fourth Dose } \\
\text { (Day 274) }\end{array}$ & 36 & 427 & 5955 \\
\hline
\end{tabular}

Study\#8388198: Following a single-dose IA injection of TLC599, DP concentration declined after 15 days but remained at similar level from 30 days to 120 days post-dose. Overall, the prolonged 120-day residence time of TLC599 in synovial joint was observed (Figure 2).

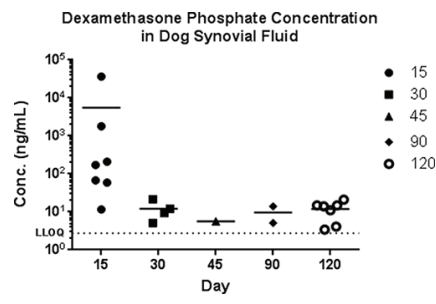

Abstract THU465 - Figure 2. Mean Concentration of DP in Dog Synovial Fluid.

Conclusion: TLC599, a novel extended-release liposome formulation of DSP, showed a long-lasting profile up to 120 days in synovial joint after a single IA injection in a preclinical dog study. In addition, no significant systemic exposure and accumulation of DP and DEX in dog plasma was observed following multiple-dose administration of TLC599. Animal studies indicate that TLC599 may be an effective and superior chronic treatment for $O A$.

\section{REFERENCE:}

[1] Zhang W, et al., OARSI recommendations for the management of hip and knee osteoarthritis, part II: OARSI evidence-based, expert consensus guidelines. Osteoarthritis Cartilage 2008;16(2): 137-62

Acknowledgement: The authors thank Yingfang Li, Jiunmin Lai, Ruixue Chen, Ph.D. and Carl Brown Ph.D. for reviewing support.

Disclosure of Interests: Tzung-Ju Wu Employee of: Current employee of Taiwan Liposome Company, Wan-Ni Yu Employee of: Current employee of Taiwan Liposome Company, Ming-Ju Wu Employee of: Current employee of Taiwan Liposome Company, Po-Chun Chang Employee of: Current employee of Taiwan Liposome Company, Sheue-Fang Shih Employee of: Current employee of Taiwan Liposome Company DOI: 10.1136/annrheumdis-2019-eular.3880

\section{THU0466 THE EVALUATION OF THE EFFECTIVENESS OF INTRA- ARTICULAR STEROID, TENOXICAM AND COMBINED STEROID-TENOXICAM INJECTIONS IN THE TREATMENT OF PATIENTS WITH KNEE OSTEOARTHRITIS}

YILMAZ Ebru . Korfez Government Hospital, Physical Therapy and Rehabilitation, Kocaeli, Turkey

Background: Intra-articular corticosteroid injections are widely applied in the treatment of symptomatic knee osteoarthritis $(\mathrm{OA})$. There is an evidence of short-term effects of intra-articular corticosteroid injection (up to 3-4 weeks), however there is no consensus for the long-term benefit of this treatment yet (1). Tenoxicam is an effective analgesic and anti-inflammatory drug for symptomatic treatment of OA. Additionally, apart from oral use, tenoxicam is also applied as an intra-articular treatment option to minimize gastrointestinal side effects of NSAIDs (2). Clinical evidence suggests that the combined use of NSAIDs and corticosteroids is synergistic (especially macular edema after cataract surgery in ophthalmology) (3)

Objectives: The aim of this study is to compare the effectiveness of intra-articular administration of these treatments and their combination and determine whether the combination of intraarticular steroid and tenoxicam was more effective for a long period rather than only tenoxicam and steroid injection alone in $\mathrm{OA}$ treatment.

Methods: 90 patients (56 female, 34 male) with diagnosis of knee osteoarthritis were randomly divided into three groups (30 patients per group): Group 1 were treated by intra-articular injection of tenoxicam. Group 2 were treated by intra-articular injection of triamcinolone hexacetonide. Group 3 were treated by intra-articular injection of triamcinolone hexacetonide combined with tenoxicam. The estimation of the severity of pain by the visual analog scale (VAS) were enrolled at baseline and 1, 3, 6 months post-injection. Additionally, the Western Ontario and McMaster Universities Index (WOMAC) was used to determine the outcome measures of pain, stiffness and physical functioning at baseline and 1, 3, 6 months post-injection. 